\title{
Role of atmospheric pollution on the natural history of idiopathic pulmonary fibrosis
}

\author{
Lucile Sesé, ${ }^{1,2,3}$ Hilario Nunes, ${ }^{2,3}$ Vincent Cottin, ${ }^{4}$ Shreosi Sanyal, ${ }^{1}$ Morgane Didier, $^{2,3}$ \\ Zohra Carton, ${ }^{2}$ Dominique Israel-Biet, ${ }^{5}$ Bruno Crestani, ${ }^{6}$ Jacques Cadranel, ${ }^{7}$ \\ Benoit Wallaert, ${ }^{8}$ Abdellatif Tazi, ${ }_{1}^{9}$ Bernard Maître, ${ }^{10}$ Grégoire Prévot, ${ }^{11}$ \\ Sylvain Marchand-Adam, ${ }^{12}$ Stéphanie Guillot-Dudoret, ${ }^{13}$ Annelyse Nardi, ${ }^{14}$ \\ Sandra Dury, ${ }^{15}$ Violaine Giraud ${ }^{16}$ Anne Gondouin, ${ }^{17}$ Karine Juvin, ${ }^{5}$ Raphael Borie, ${ }^{6}$ \\ Marie Wislez, ${ }^{7}$ Dominique Valeyre, ${ }^{2,3}$ Isabella Annesi-Maesano ${ }^{1}$
}

For numbered affiliations see end of article.

\section{Correspondence to}

Hilario Nunes, Service de Pneumologie, Hôpital Avicenne, 125 Rue de Stalingrad 93000 Bobigny, France; hilario.nunes@ aphp.fr

Received 8 January 2017 Revised 23 June 2017 Accepted 24 July 2017 Published Online First 10 August 2017

\section{SLinked}

- http://dx.doi.org/10.1136/ thoraxjnl-2017-210808

\section{CrossMark}

To cite: Sesé $\mathrm{L}$, Nunes $\mathrm{H}$ Cottin V, et al. Thorax 2018:73:145-150.

\section{ABSTRACT}

Introduction Idiopathic pulmonary fibrosis (IPF)

has an unpredictable course corresponding to various profiles: stability, physiological disease progression and rapid decline. A minority of patients experience acute exacerbations (AEs). A recent study suggested that ozone and nitrogen dioxide might contribute to the occurrence of AE. We hypothesised that outdoor air pollution might influence the natural history of IPF.

Methods Patients were selected from the French cohort COhorte Flbrose (COFI), a national multicentre longitudinal prospective cohort of IPF $(n=192)$. Air pollutant levels were assigned to each patient from the air quality monitoring station closest to the patient's geocoded residence. Cox proportional hazards model was used to evaluate the impact of air pollution on $A E$, disease progression and death.

Results Onset of AEs was significantly associated with an increased mean level of ozone in the six preceding weeks, with an HR of $1.47(95 \% \mathrm{Cl} 1.13$ to 1.92$)$ per $10 \mu \mathrm{g} / \mathrm{m}^{3}(\mathrm{p}=0.005)$. Cumulative levels of exposure to particulate matter $\mathrm{PM}_{10}$ and $\mathrm{PM}_{25}$ were above $\mathrm{WHO}$ recommendations in $34 \%$ and $100 \%$ of patients, respectively. Mortality was significantly associated with increased levels of exposure to $\mathrm{PM}_{10}(H R=2.01$, $95 \% \mathrm{Cl} 1.07$ to 3.77$)$ per $10 \mu \mathrm{g} / \mathrm{m}^{3}(\mathrm{p}=0.03)$, and $\mathrm{PM}_{25}$ (HR=7.93, 95\% Cl 2.93 to 21.33$)$ per $10 \mu \mathrm{g} / \mathrm{m}^{3}$ $(\mathrm{p}<0.001)$.

Conclusion This study suggests that air pollution has a negative impact on IPF outcomes, corroborating the role of ozone on AEs and establishing, for the first time, the potential role of long-term exposure to $\mathrm{PM}_{10}$ and $\mathrm{PM}_{2.5}$ on overall mortality.

\section{INTRODUCTION}

Idiopathic pulmonary fibrosis (IPF) is the most common and most severe form of idiopathic interstitial pneumonia, with few treatment options and a median survival after diagnosis between 24 and 36 months. ${ }^{1-4}$ The natural history of IPF has not been fully elucidated and remains unpredictable. ${ }^{56}$ While the majority of patients experience slow and gradual progression on pulmonary function tests (PFTs), some remain relatively stable and others experience rapid decline. A minority of patients

\section{Key messages}

What is the key question?

- Does outdoor air pollution influence the natural history of idiopathic pulmonary fibrosis (IPF)?

What is the bottom line?

- The occurrence of acute exacerbations is significantly associated with an increased mean level of ozone, and long-term exposure to elevated levels of $\mathrm{PM}_{10}$ and $\mathrm{PM}_{25}$ is a risk factor for mortality in patients with IPF.

Why read on?

- This is the first study to assess the effect of air pollution on the entire natural history of IPF and more specifically the impact of $\mathrm{PM}_{2.5}$.

present sudden and unexplained deterioration of the disease, described as acute exacerbation (AE). ${ }^{4}$

$\mathrm{AE}$ is defined as worsening of dyspnoea in the previous 30 days, combined with the emergence of new parenchymal opacities on high-resolution CT (HRCT), including diffuse ground glass attenuation or consolidations. Potential causes of abrupt respiratory deterioration, such as infection, congestive heart failure or pulmonary embolism, must be ruled out. ${ }^{7-9}$ Several triggers have been described, including surgical lung biopsy, ${ }^{7}$ microaspiration ${ }^{10}$ and viral infections. ${ }^{11}$ AEs are responsible for high mortality, accounting for about $21 \%-40 \%$ of all deaths of patients with IPF. ${ }^{912}{ }^{13}$ Disease progression of IPF is usually defined by at least $10 \%$ decrease of the predicted value for forced vital capacity (FVC\%pred) or at least $15 \%$ decrease of the predicted value for diffusing capacity of the lung for carbon monoxide (DLco\%pred) from baseline values, respectively. ${ }^{5}$

Although IPF is a disease of unknown aetiology, a number of potential environmental risk factors have been identified, such as cigarette smoking ${ }^{14}$ and exposure to metal and wood dusts. ${ }^{15}$

The impact of air pollution has now been clearly established in various airway diseases. It has been associated with poorly controlled asthma, ${ }^{16}$ altered lung function growth, ${ }^{17}$ increased incidence of 
chronic obstructive pulmonary disease (COPD) ${ }^{18}$ COPD exacerbations ${ }^{19}$ and respiratory-related mortality. ${ }^{20}$ Recently, using data from a South Korean IPF cohort, Johannson $e t a l^{21}$ showed a significant association between $\mathrm{AE}$ and increased urban background levels of ozone $\left(\mathrm{O}_{3}\right)$ and nitrogen dioxide $\left(\mathrm{NO}_{2}\right)$ close to the residential addresses in the previous 6 weeks. ${ }^{21}$ However, these findings have not yet been validated in another cohort, although the type and degree of pollution are known to vary considerably throughout the world. In addition, the study assessed the role of coarse particulate matter $\left(\mathrm{PM}_{10}\right)$ but not that of fine and ultrafine particulate matter $\left(\mathrm{PM}_{2.5}\right)$ and may therefore have missed an important issue. Indeed, $\mathrm{PM}_{10}$ can penetrate the bronchi, whereas $\mathrm{PM}_{2.5}$ can reach the pulmonary alveoli, which could be particularly relevant in the natural history of IPF.

We hypothesised that outdoor air pollution could influence the natural history of IPF and investigated the impact of major urban air pollutants, namely $\mathrm{NO}_{2}, \mathrm{O}_{3}, \mathrm{PM}$ with an aerodynamic diameter of $10 \mathrm{~mm}\left(\mathrm{PM}_{10}\right)$ and $2.5 \mathrm{~mm}\left(\mathrm{PM}_{2.5}\right)$, on $\mathrm{AE}$, disease progression and death in a national longitudinal prospective cohort in France.

\section{PATIENTS AND METHODS Source population}

Patients were selected from the French cohort COhorte FIbrose (COFI), a national multicentre prospective study on the natural history of IPF. The primary endpoint of the COFI study was to determine the factors associated with progression-free survival by focusing on several events, including disease progression, $\mathrm{AE}$ and death. The recruitment period extended from December 2007 to December 2010, with 5-year follow-up. Patients included in the cohort were required to have a diagnosis of incident IPF less than 9 months before inclusion, according to the American Thoracic Society/European Respiratory Society consensus criteria. ${ }^{3}$

Patients were followed every 3 months. Health events were defined as follows:

- AE: (1) worsening dyspnoea $\leq 1$ month, (2) decrease in arterial oxygen tension (or pressure) $\mathrm{PaO}_{2}>10 \mathrm{~mm} \mathrm{Hg}$ compared with the results of the previous scheduled visit, (3) new opacities on HRCT (ground glass attenuation or consolidations) and (4) exclusion of other causes of worsening.

- Disease progression: (1) absolute decrease in FVC $>10 \%$ pred or absolute decrease in DLco $>15 \%$ pred compared with baseline values, (3) within $>6$ months and (3) exclusion of other causes of worsening.

\section{Study population}

From the COFI cohort, we excluded patients for whom the residential address or air pollution exposure measurements were unavailable, and those with no clinical follow-up. Baseline characteristics and the date of diagnosis of $\mathrm{AE}$, disease progression and death were collected prospectively, from December 2007 to December 2014.

For the purposes of the study, three health events were considered in successive analyses. The occurrence of an event did not result in excluding the patient for a potential following event. For example, a patient may initially show a disease progression and thereafter an $\mathrm{AE}$ or die in further follow-up. However, a patient who presented an $\mathrm{AE}$ as the first event could not develop a disease progression, as an $\mathrm{AE}$ is ultimately the equivalent of a rapid progression. We modelled the three events separately because we assumed that the exposure period was different for $\mathrm{AE}$, disease progression and death.

First, we considered patients who experienced an $\mathrm{AE}$ at some point during the study period (cases). Each of these cases was compared with all other patients from the cohort at risk at the date of the event, who had not yet experienced an $\mathrm{AE}$ and who did not experience an AE during the 6 weeks following the date of the case event (pooled controls). For patients who experienced more than one $\mathrm{AE}$, only the first event was included in the analysis.

Similarly, we compared patients with disease progression to the other patients.

Lastly, we compared the exposures of patients who died from any cause to those of the other patients.

All patients enrolled in the COFI cohort provided their informed consent, and the study was approved by the local ethics committee (Comité de Protection des Personnes Ile-deFrance) and by the French data protection authority (CNIL: 908198).

\section{Air pollution data}

French Regional Air Quality Agencies (Airparif, ATMO Picardie, ATMO Champagne Ardenne, Lig'Air, Air Rhone-Alpes, Airbreizh, ORAMIP, respectively) provided the hourly concentrations of $\mathrm{NO}_{2}, \mathrm{O}_{3}, \mathrm{PM}_{10}$ and $\mathrm{PM}_{25}$ from rural and traffic ambient air monitoring stations, during the study period (from December 2007 to December 2014). Air pollutants levels obtained from the air quality monitoring station closest to the patient's residential address were assigned to each patient. The distance between the monitoring station and the patient's residential address was identified by the Google Map Distance Calculator after having geocoded the patient's address.

Mean exposure was calculated by determining the average of all hourly concentrations of $\mathrm{NO}_{2}, \mathrm{O}_{3}, \mathrm{PM}_{10}$ and $\mathrm{PM}_{25}$ during the exposure period of each IPF event. The exposure period was defined as 6 weeks preceding the date of $\mathrm{AE}$, based on the study by Johannson $e t$ al. ${ }^{21}$ Based on the assumption that longterm pollution exposure had an impact on disease progression or death, the exposure period was defined as the entire period from inclusion to the date of the event or censoring. Cumulative exposure was expressed as the average concentration of each pollutant during the exposure period.

Air pollution data were divided into two 6-month seasonal periods (warm season, from May to October, and cool season, from November to April). ${ }^{22}$

\section{Statistical analysis}

Comparisons were performed using Student's t-test and $\chi^{2}$ test, as appropriate.

Patients were followed from inclusion until death or lung transplantation or until December 2014. Transplant patients were considered as alive at the date of transplantation. A Cox proportional hazards model was used to evaluate the short-term impact of air pollution on AEs of IPF. ${ }^{23}$ The event of interest was the first AE. For each pollutant, we compared the mean concentration observed during the exposure period, corresponding to 6 weeks before AE. All patients at risk were used as pooled controls for each case. The model was adjusted for warm and cool seasons, as the air pollution composition can vary according to meteorological influences. ${ }^{24}$ The model was also adjusted for risk factors of exacerbation described in from the literature, including smoking status and baseline FVC\%pred and DLco\%pred. 
Table 1 Baseline characteristics of patients

\begin{tabular}{llll}
\hline Characteristics & $\begin{array}{l}\text { No acute } \\
\text { exacerbation } \\
\mathbf{n}=152\end{array}$ & $\begin{array}{l}\text { Acute exacerbation } \\
\mathbf{n}=40\end{array}$ & p Value \\
\hline Age (years) & $67.9 \pm 11.2$ & $68.0 \pm 8.2$ & 0.95 \\
\hline BMI & $27.5 \pm 4.3$ & $27.7 \pm 4.5$ & 0.89 \\
\hline Males & $118(77.6)$ & $30(75)$ & 0.72 \\
\hline Smokers & & & \\
\hline \multicolumn{1}{c}{ Never } & $36(23.7)$ & $13(32.5)$ & \\
\hline \multicolumn{1}{|c}{ Former } & $11(7.2)$ & $2(5.0)$ & 0.58 \\
\hline \multicolumn{1}{c}{ Current } & $96(63.2)$ & $24(60.0)$ & \\
\hline TLC\% predicted & $69.9 \pm 16.0$ & $64.7 \pm 13.0$ & 0.06 \\
\hline FVC \% predicted & $76.8 \pm 20.3$ & $73.4 \pm 15.1$ & 0.33 \\
\hline DLco \% predicted & $47.6 \pm 16.5$ & $42.2 \pm 13.0$ & 0.05 \\
\hline FEV $\%$ predicted & $81.5 \pm 21.5$ & $78.1 \pm 16.2$ & 0.41 \\
\hline Prednisone* & $60(39.4)$ & $16(40)$ & 0.95 \\
\hline SLB & $51(33.8)$ & $19(47)$ & 0.13 \\
\hline GORD & $60(39.4)$ & $19(31.7)$ & 0.40 \\
\hline Death & $73(48)$ & $36(90.0)$ & $<0.001$ \\
\hline Data & & \\
\hline
\end{tabular}

Data are presented as mean \pm SD or $\mathrm{n}(\%)$.

*Prednisone use at inclusion or within the first 6 months after inclusion. $\mathrm{BMI}$, body mass index; DLco, diffusing capacity of the lung for carbon monoxide; FEV, forced expiratory volume; FVC, forced vital capacity; GORD, gastro-oesophageal reflux disease; SLB, surgical lung biopsy; TLC, total lung capacity.

A Cox proportional hazards model was conducted to estimate the impact of cumulative air pollution on disease progression. Cumulative exposure was calculated over the entire period from inclusion to the date of the event or censoring. The model was adjusted for age. The same methodology was used to study the impact of cumulative exposure on mortality. The model was adjusted for age, smoking status, and baseline FVC\%pred and DLco\%pred.

Statistic analysis was performed using R software V.3.0.1, and statistical significance was defined as a $\mathrm{p}$ value $<0.05$.

\section{RESULTS}

Of the 245 patients included in COFI, 25 patients with missing residential address, 10 patients with missing air pollution data, 11 patients with no clinical follow-up and 7 patients living more than $30 \mathrm{~km}$ from the monitoring station were excluded. Among the 192 patients with IPF selected, 40 experienced at least one episode of AE during follow-up (34.7 \pm 22.3 months). About one-half of the population experienced disease progression, as defined on PFTs $(n=90)$, and the majority of patients died $(n=109)$, and 17 patients were transplanted.

As expected, patients with AE had more impaired DLco $(p=0.05)$ and higher rate of death $(p<0.001)$. No significant difference was observed between groups in terms of age at inclusion, sex ratio, smoking status, FVC, gastro-oesophageal reflux and corticosteroid therapy (table 1 ).

The cumulative exposure levels for the overall population were $19.46( \pm 3.25) \mu \mathrm{g} / \mathrm{m}^{3}$ for $\mathrm{PM}_{10}$ and $26.23( \pm 3.43) \mu \mathrm{g} / \mathrm{m}^{3}$ for $\mathrm{PM}_{2,5} ; 34 \%$ and $100 \%$ of patients had exposure levels above the WHO recommendations for $\mathrm{PM}_{10}$ and $\mathrm{PM}_{2.5}$, respectively.

\section{Short-term effect of air pollution on AE}

$\mathrm{AE}$ events were significantly associated with a higher mean concentration of $\mathrm{O}_{3}$ during the exposure period, with an HR
Table 2 Short-term effect of air pollution on acute exacerbations

\begin{tabular}{llll}
\hline Exposure & Increase & HR $(95 \% \mathrm{Cl})$ & $\mathrm{p}$ Value \\
\hline $\mathrm{O}_{3}$ & $10 \mu \mathrm{g} / \mathrm{m}^{3}$ & $1.47(1.13$ to 1.92$)$ & 0.005 \\
$\mathrm{NO}_{2}$ & $10 \mu \mathrm{g} / \mathrm{m}^{3}$ & $0.92(0.68$ to 1.24$)$ & 0.584 \\
$\mathrm{PM}_{10}$ & $10 \mu \mathrm{g} / \mathrm{m}^{3}$ & $0.80(0.52$ to 1.27$)$ & 0.347 \\
$\mathrm{PM}_{2.5}$ & $10 \mu \mathrm{g} / \mathrm{m}^{3}$ & $1.29(0.65$ to 2.57$)$ & 0.463 \\
\hline
\end{tabular}

Cox proportional hazards model adjusted on season, FVC\% predicted at baseline, DLco\% predicted at baseline and smoking status.

$\mathrm{NO}_{2}$, nitrogen dioxide; $\mathrm{O}_{3}$, ozone; $\mathrm{PM}_{10}$ and $\mathrm{PM}_{25}$, particles with a $50 \%$ cut-off aerodynamic diameter of $10 \mu \mathrm{m}$ and $2.5 \mu \mathrm{m}$.

of 1.47 (95\% CI 1.13 to 1.92$)$ per $10 \mu \mathrm{g} / \mathrm{m}^{3}(\mathrm{p}=0.005)$. No association was observed between $\mathrm{AE}$ and $\mathrm{NO}_{2}, \mathrm{PM}_{10}$ and $\mathrm{PM}_{2.5}$ (table 2).

\section{Long-term effect of cumulative air pollution exposure on disease progression}

Disease progression was not associated with increased cumulative concentrations of $\mathrm{NO}_{2}, \mathrm{O}_{3}, \mathrm{PM}_{10}$ or $\mathrm{PM}_{2.5}$ (table 3).

\section{Long-term effect of cumulative air pollution exposure on mortality}

Mortality was significantly associated with increased cumulative exposure to $\mathrm{PM}_{10}$ with an HR of 2.01 (95\% CI 1.07 to 3.77) per $10 \mu \mathrm{g} / \mathrm{m}^{3}(\mathrm{p}=0.03)$ and to $\mathrm{PM}_{2.5}$ with a HR of 7.93 (95\% CI 2.93 to 21.33$)$ per $10 \mu \mathrm{g} / \mathrm{m}^{3}(\mathrm{p}<0.001)$.

No association was observed between IPF mortality and $\mathrm{NO}_{2}$ or $\mathrm{O}_{3}$ (table 4).

\section{DISCUSSION}

This is the first study to assess the effect of air pollution on the natural history of IPF and more specifically the impact of $\mathrm{PM}_{2.5}$. Our results confirm that short-term exposure to increased levels of ozone is a risk factor for $\mathrm{AE}$ and demonstrate, for the first time, that long-term exposure to elevated levels of $\mathrm{PM}_{10}$ and $\mathrm{PM}_{2.5}$ is a risk factor for mortality in patients with IPF.

A recent publication proposed potential mechanisms by which air pollution, via oxidative stress, inflammation and telomere shortening, might trigger AEs or accelerate progression of interstitial lung diseases, in genetically susceptible individuals. ${ }^{25}$ In the present study, analysis of the impact of air pollution on the natural history of IPF could not be restricted to a same exposure period for each event. We chose a 6-week exposure period for $\mathrm{AE}$, as reported in the study by Johannson et al, in order to allow for a potential lag-time from pollutant exposure to onset of symptoms. We also hypothesised that disease progression and death could be associated with major long-term exposure to pollution, and therefore also focused on cumulative exposure

Table 3 Association of cumulative air pollution exposure and disease progression

\begin{tabular}{llll}
\hline Exposure & Increase & HR $(95 \% \mathrm{Cl})$ & p Value \\
\hline $\mathrm{O}_{3}$ & $10 \mu \mathrm{g} / \mathrm{m}^{3}$ & $1.06(0.74$ to 1.54$)$ & 0.72 \\
$\mathrm{NO}_{2}$ & $10 \mu \mathrm{g} / \mathrm{m}^{3}$ & $1.09(0.85$ to 1.40$)$ & 0.52 \\
$\mathrm{PM}_{10}$ & $10 \mu \mathrm{gg} / \mathrm{m}^{3}$ & $1.03(0.51$ to 2.08$)$ & 0.92 \\
$\mathrm{PM}_{2.5}$ & $10 \mu \mathrm{g} / \mathrm{m}^{3}$ & $1.89(0.68$ to 5.23$)$ & 0.22 \\
\hline
\end{tabular}

Cox proportional hazards model adjusted on age, FVC \% predicted at base line and DLco $\%$ predicted at baseline.

$\mathrm{NO}_{2}$, nitrogen dioxide; $\mathrm{O}_{3^{\prime}}$, ozone; $\mathrm{PM}_{10}$ and $\mathrm{PM}_{2.5}$, particles with a $50 \%$ cut-off aerodynamic diameter of $10 \mu \mathrm{m}$ and $2.5 \mu \mathrm{m}$. 


\begin{tabular}{|c|c|c|c|}
\hline Exposure & Increase & HR $(95 \% \mathrm{Cl})$ & $\mathrm{p}$ Value \\
\hline $\mathrm{O}_{3}$ & $10 \mu \mathrm{g} / \mathrm{m}^{3}$ & 0.89 (0.66 to 1.18 ) & 0.43 \\
\hline $\mathrm{NO}_{2}$ & $10 \mu \mathrm{g} / \mathrm{m}^{3}$ & 1.01 (0.79 to 1.29$)$ & 0.90 \\
\hline $\mathrm{PM}_{10}$ & $10 \mu \mathrm{g} / \mathrm{m}^{3}$ & 2.01 (1.07 to 3.77 ) & 0.03 \\
\hline $\mathrm{PM}_{2.5}$ & $10 \mu \mathrm{g} / \mathrm{m}^{3}$ & 7.93 (2.93 to 21.33 ) & $<0.001$ \\
\hline
\end{tabular}

Cox proportional hazards model adjusted on age, FVC\% predicted at base line and DLco\% predicted at base line and smoking status.

$\mathrm{NO}_{2^{\prime}}$ nitrogen dioxide; $\mathrm{O}_{3^{\prime}}$ ozone; $\mathrm{PM}_{10}$ and $\mathrm{PM}_{2.5}$, particles with a $50 \%$ cut-off aerodynamic diameter of $10 \mu \mathrm{m}$ and $2.5 \mu \mathrm{m}$.

to air pollutants over the entire period from IPF diagnosis to the date of the event or censoring.

The major original result of this study is the relationship between long-term cumulative exposure to elevated levels of $\mathrm{PM}_{10}$ and $\mathrm{PM}_{2.5}$ and the risk of mortality in patients with IPF. All patients were exposed to $\mathrm{PM}_{25}$ concentrations higher than the WHO recommendations, and $34 \%$ patients were exposed to higher than recommended $\mathrm{PM}_{10}$ (WHO recommends not exceeding an annual concentration of $20 \mu \mathrm{g} / \mathrm{m}^{3}$ for $\mathrm{PM}_{10}$ and $10 \mu \mathrm{g} / \mathrm{m}^{3}$ for $\mathrm{PM}_{2.5}{ }^{26}$ ). Adjusting for age, smoking status, FVC and DLco, the HR for $\mathrm{PM}_{10}$ and $\mathrm{PM}_{2.5}$ cumulative exposure was $2.01(95 \%$ CI 1.07 to 3.77$)$ per $10 \mu \mathrm{g} / \mathrm{m}^{3}$ and 7.93 (95\% CI 2.93 to 21.33 ) per $10 \mu \mathrm{g} / \mathrm{m}^{3}$, respectively. Noteworthy, the South Korean study, conducted in a longitudinal IPF cohort in Seoul, failed to find a link between the mean exposure to $\mathrm{PM}_{10}$ over the entire follow-up period and mortality ( $\mathrm{HR}=0.96,95 \% \mathrm{CI}$ (0.84 to 1.08$), p=0.4794$, results kindly provided by Johannson et al) and it does not mention the exposure to $\mathrm{PM}_{2.5}$. These discrepant findings for $\mathrm{PM}_{10}$ might be explained by differences in the exposure estimates between the two studies because of a different density of monitoring stations in France and Korea, or by the fact that the levels of $\mathrm{PM}_{10}$ vary less in Korea. Most of our patients lived in Greater Parisian agglomeration $(n=133)$ where the number of monitoring stations is high (70 stations spread over a $100 \mathrm{~km}$ radius around Paris). Moreover, the positive association found for both $\mathrm{PM}_{10}$ and $\mathrm{PM}_{2.5}$ strengthens the probable role of fine particles on IPF mortality.

Fine particles are deposited deeply in the respiratory tract. PM components have the ability to trigger and/or enhance free radical reactions in cells and tissues. Prolonged exposure to PM induces oxidative stress and telomere erosion ${ }^{27}$ and inflammation that become systemic, mechanisms underlying the development of chronic diseases and mortality. Thus, PM are responsible for both short-term and long-term health effects. Several cohort studies have demonstrated that long-term exposure to $\mathrm{PM}_{10}$ and $\mathrm{PM}_{2.5}$ is associated with cardiopulmonary mortality, ${ }^{28} 2$ consistent with our finding that cumulative exposure to $\mathrm{PM}_{10}$ and $\mathrm{PM}_{25}$ increases the risk of death in patients with IPF.

Ozone is formed in the atmosphere by photochemical reactions in the presence of light and precursor pollutants. Ozone is known to induce airway hyper-reactivity and airway inflammation $^{30} 31$ and increase the risk of exacerbation in asthma. ${ }^{1632}$

Our results concerning the short-term effects of pollution on AEs are in agreement with those reported by Johannson et al showing an association between $\mathrm{AE}$ and increases in mean level, maximum level and number of exceedances above accepted standards of ozone $(\mathrm{HR}=1.57,95 \% \mathrm{CI} 1.09-2.24 ; \mathrm{HR}=1.42$, 95\% CI 1.11 to 1.82 ; and $\mathrm{HR}=1.51,95 \% \mathrm{CI}: 1.17$ to 1.94 , respectively). ${ }^{21}$ If we express our results as in the Korean study, a lower risk was observed in our study with an HR of 1.039
(95\% CI 1.012 to $1.067, p=0.005$ ), after adjustments for season, smoking status, and baseline FVC and DLco. This lower risk can be explained by several differences in terms of exposure levels, geographical zones, adjustment factors and genetic/ ethnic aspects. Having said that, such consistent results obtained despite the relatively small sample size of these two studies (compared with the large populations usually included in air pollution studies) strongly support our findings.

The diagnostic criteria of AE have changed over recent years. In the COFI cohort, we applied the criteria proposed by Akira et $a l$, the criteria most widely used at the time of study initiation, whereas Johannson et al used those of Collard et al published in 2007. The primary difference between these sets of criteria is the requirement for invasive endotracheal aspirate or BAL to ascertain a diagnosis of 'definite' AE in Collard et al definition. Otherwise, acute deterioration was termed 'suspected' AE. In the COFI, a potential cause for acute deterioration was systematically investigated, including routine non-invasive tests for infectious organisms. However, as clinical evaluation was left to investigator's judgement, only a minority of our patients underwent bronchoscopy. According to Collard et al's definition, 32 patients (80\%) had 'suspected' AE and eight patients (20\%) had 'definite' AE, as compared with $31 \%$ and $69 \%$, respectively, in the Korean study. This striking difference just reflects the heterogeneity of AE management between centres. Nevertheless, it should be underlined that, in an attempt to better fit into real life practice, exclusion of infection is no longer mandatory in the 2016 revised definition of $\mathrm{AE} . .^{33}$ Moreover, there is little clinical or biological support for distinguishing idiopathic from non-idiopathic respiratory events, so that the impact of AE definition between the French and Korean studies is unlikely.

$\mathrm{NO}_{2}$ is a marker of traffic-related air pollution. Several studies in the literature have shown that high short-term exposure to $\mathrm{NO}_{2}$ is responsible for exacerbations of COPD or asthma. ${ }^{163435}$ Unlike Johannson et al, we did not find any association between $\mathrm{AE}$ and short-term $\mathrm{NO}_{2}$ exposure, which is probably due to a lack of power, and possibly because the magnitude of traffic-related air pollution is higher in South Korea than in France (air pollution in the world: real time air quality index: http://waqi. info/). We did not find any association between disease progression of IPF and cumulative exposure to $\mathrm{O}_{3}, \mathrm{NO}_{2}, \mathrm{PM}_{10}$ or $\mathrm{PM}_{2.5}$. However, all HRs were greater than one, suggesting a possible low-risk link that have been missed due to insufficient power. Interestingly, Richards et al reported a correlation between ambient air pollution and longitudinal changes in pulmonary function of patients with IPF. In a longitudinal cohort of 325 patients, they found that short-term $\mathrm{O}_{3}$ and $\mathrm{SO}_{2}$ exposure were both significantly associated with DLco decline over time but not $\mathrm{PM}_{10}$ exposure. $^{36}$

Our study has several limitations. Although it is a national multicentre cohort, the population is relatively small for this type of study, which could have prevented demonstration of the other impacts of air pollution. Second, our study is subject to exposure misclassification. The variable distance between the patient's residence and the nearest air quality monitoring station may have led to underestimation or overestimation of real exposure. Moreover, exposure to air pollution at home or in the workplace, which has a recognised role in respiratory diseases, could not be taken into account. In addition, no information was available concerning temperature and relative humidity, and adjustments were based on 6-month seasonal periods. However, this method has already been used in several similar studies. ${ }^{22}$ Last, the exclusion of cases living in areas where measurements were not available may have excluded more rural regions. 
However, there was no significant difference between the rates of $\mathrm{AE}(20.8 \%$ vs $20.0 \%, \mathrm{p}=1)$ and death $(56.8 \%$ vs $20.0 \%$, $\mathrm{p}=0.17)$ between patients included and those not covered by a monitoring station. Similarly, the exclusion of cases lost to follow-up may have excluded healthiest or sickest patients not attending clinic visits. It is true that patients lost to follow-up had a significantly less altered DLco than the whole population included $(59.5 \% \pm 20.2 \%$ vs $46.4 \pm 15.9 \%, p=0.01)$, but their FVC was similar $(87.6 \% \pm 22.9 \%$ vs $75.2 \% \pm 23.5 \%, \mathrm{p}=0.19)$. Excluding these patients may have induced a potential bias even though their number was small.

Conversely, one of the strengths of this study is the longitudinal and prospective nature of the cohort, limiting the event misclassification bias (AE, disease progression and death).

This study suggests that air pollution may affect IPF outcomes, corroborating the role of ozone on $\mathrm{AE}$ and establishing, for the first time, the potential role of long-term exposure to $\mathrm{PM}_{10}$ and $\mathrm{PM}_{25}$ on overall mortality. These results, which are in line with WHO recommendations to reduce pollutant emissions, ${ }^{26}$ require further investigation. In future studies, in order to improve exposure measurements, patients with IPF could be asked to wear a sensor all day long to more accurately quantify indoor and outdoor environmental air quality.

\section{Author affiliations}

EPAR, Université Pierre et Marie, Paris, France

${ }^{2}$ Service de Pneumologie, AP-HP, Hôpital Avicenne, Bobigny, France

${ }^{3}$ Université Paris, Bobigny, France

${ }^{4}$ Service de Pneumologie, Hôpital Louis Pradel, Lyon, France

${ }^{5}$ Service de Pneumologie, AP-HP, Hôpital HEGP, Paris, France

${ }^{6}$ Service de Pneumologie, AP-HP, Hôpital Bichat, Paris, France

Service de Pneumologie, AP-HP, Hôpital Tenon, Paris, France

${ }^{8}$ Service de Pneumologie, Hôpital Albert Calmette, Lille, France

${ }^{9}$ Service de Pneumologie, AP-HP, Hôpital Saint-Louis, Paris, France

${ }^{10}$ Service de Pneumologie, AP-HP, Hôpital Henri-Mondor, Créteil, France

${ }^{11}$ Service de Pneumologie, Hôpital Larrey, Centre Hospitalier Universitaire de

Toulouse, Toulouse, France

${ }^{12}$ Service de Pneumologie, Hôpital Bretonneau Centre Hospitalier Universitaire de

Tours, Paris, France

${ }^{13}$ Service de Pneumologie, Hôpital Pontchaillou, Centre Hospitalier Universitaire de Rennes, Rennes, France

${ }^{14}$ Service de Pneumologie, Nouvel Hôpital Civil, Centre Hospitalier Universitaire de Strasbourg, Strasbourg, France

${ }^{15}$ Service de Pneumologie, Hôpital Maison Blanche, Centre Hospitalier Universitaire de Reims, Reims, France

${ }^{16}$ Service de Pneumologie, AP-HP, Hôpital Ambroise Paré, Boulogne, France

${ }^{17}$ Service de Pneumologie, Hôpital Jean Minjoz, Centre Hospitalier Universitaire de

Besançon, Besançon, France

Acknowledgements The authors would like to thank Professor Vittinghoff for his advice on statistical analysis and all Air Quality Regional Agencies for providing us with air pollution data.

Contributors (1) Substantial contributions to the conception or design of the work; or the acquisition, analysis or interpretation of data for the work; (2) drafting the work or revising it critically for important intellectual content; (3) final approval of the version to be published; and (4) agreement to be accountable for all aspects of the work in ensuring that questions related to the accuracy or integrity of any part of the work are appropriately investigated and resolved. All persons designated as authors meet all four ICMJE criteria for authorship (LS, HN, VC, SS, MD, ZC, DI-B, BC, JC, BW, AT, BM, GP, SM-A, SG-D, AN, SD, VG, AG, KJ, RB, MW, DV and IA-M).

Funding Chancellerie des Universités de Paris (Legs Poix, grant \#637), PHRC (grant \# AOR 07076) and the Medical Research Foundation.

Competing interests $\mathrm{HN}$ reports other from Intermune, other from Roche, other from Boehringer- Ingelheim, other from Sanofi, during the conduct of the study; other from Centocor, outside the submitted work; DV reports personal fees from Intermune, personal fees from Roche, personal fees from Boehringer Ingelheim, personal fees from Intermune, Roche, Boehringer Ingelheim, outside the submitted work. Dr AG reports grants and personal fees from Boehringer, personal fees from Roche, outside the submitted work. GP reports personal fees from Actelion, Bayer, Boehringer Ingelheim, GSK, Roche, outside the submitted work. VC reports personal fees from Actelion, Bayer, Biogen Idec, Boehringer Ingelheim, Gilead, GSK, MSD, Novartis, Pfizer, Roche/Intermune, Sanofi, grants from Actelion, Boehringer Ingelheim, GSK, Pfizer and Roche and personal fees from Boehringer Ingelheim, outside the submitted work. All other authors have no competing interests to declare.

Ethics approval Ethics Committee (Comité de Protection des Personnes Ile-deFrance) and by the French data protection authority (CNIL: 908198).

Provenance and peer review Not commissioned; externally peer reviewed.

(C) Article author(s) (or their employer(s) unless otherwise stated in the text of the article) 2018. All rights reserved. No commercial use is permitted unless otherwise expressly granted.

\section{REFERENCES}

1 Bjoraker JA, Ryu JH, Edwin MK, et al. Prognostic significance of histopathologic subsets in idiopathic pulmonary fibrosis. Am J Respir Crit Care Med 1998;157:199-203.

2 Daniil ZD, Gilchrist FC, Nicholson AG, et al. A histologic pattern of nonspecific interstitial pneumonia is associated with a better prognosis than usual interstitial pneumonia in patients with cryptogenic fibrosing alveolitis. Am J Respir Crit Care Med 1999;160:899-905.

3 Society AT. American Thoracic Society. Idiopathic pulmonary fibrosis: diagnosis and treatment. International consensus statement. American Thoracic Society (ATS), and the European Respiratory Society (ERS). Am J Respir Crit Care Med 2000;161:646-64.

4 Raghu G, Collard HR, Egan JJ, et al. An official ATS/ERS/JRS/ALAT statement: idiopathic pulmonary fibrosis: evidence-based guidelines for diagnosis and management. Am J Respir Crit Care Med 2011;183:788-824.

5 Raghu G. Idiopathic pulmonary fibrosis. A rational clinical approach. Chest 1987:92:148-54

6 Martinez FJ, Safrin S, Weycker D, et al. The clinical course of patients with idiopathic pulmonary fibrosis. Ann Intern Med 2005;142:963-7.

7 Kondoh Y, Taniguchi H, Kawabata Y, et al. Acute exacerbation in idiopathic pulmonary fibrosis. analysis of clinical and pathologic findings in three cases. Chest 1993;103:1808-12

8 Akira M, Hamada H, Sakatani M, et al. CT findings during phase of accelerated deterioration in patients with idiopathic pulmonary fibrosis. AJR Am J Roentgenol 1997;168:79-83.

9 Collard HR, Moore BB, Flaherty KR, et al. Acute exacerbations of idiopathic pulmonary fibrosis. Am J Respir Crit Care Med 2007;176:636-43.

10 Lee JS, Song JW, Wolters PJ, et al. Bronchoalveolar lavage pepsin in acute exacerbation of idiopathic pulmonary fibrosis. Eur Respir J 2012;39:352-8.

11 Wootton SC, Kim DS, Kondoh Y, et al. Viral infection in acute exacerbation of idiopathic pulmonary fibrosis. Am J Respir Crit Care Med 2011;183:1698-702.

12 Song JW, Hong SB, Lim CM, et al. Acute exacerbation of idiopathic pulmonary fibrosis: incidence, risk factors and outcome. Eur Respir J 2011;37:356-63.

13 Kishaba T, Tamaki H, Shimaoka Y, et al. Staging of acute exacerbation in patients with idiopathic pulmonary fibrosis. Lung 2014;192:141-9.

14 Baumgartner KB, Samet JM, Stidley CA, et al. Cigarette smoking: a risk factor for idiopathic pulmonary fibrosis. Am J Respir Crit Care Med 1997;155:242-8.

15 Hubbard R, Lewis S, Richards K, et al. Occupational exposure to metal or wood dust and aetiology of cryptogenic fibrosing alveolitis. The Lancet 1996;347:284-9.

16 Mann JK, Balmes JR, Bruckner TA, et al. Short-term effects of air pollution on wheeze in asthmatic children in Fresno, California. Environ Health Perspect 2010;118:1497-502.

17 Gauderman WJ, Gilliland GF, Vora H, et al. Association between air pollution and lung function growth in Southern California children: results from a second cohort. Am J Respir Crit Care Med 2002;166:76-84.

18 Schikowski T, Sugiri D, Ranft U, et al. Long-term air pollution exposure and living close to busy roads are associated with COPD in women. Respir Res 2005;6:152.

19 Dominici F, Peng RD, Bell ML, et al. Fine particulate air pollution and hospital admission for cardiovascular and respiratory diseases. JAMA 2006;295:1127-34.

20 Jerrett M, Burnett RT, Pope CA, et al. Long-term ozone exposure and mortality. N Engl J Med 2009;360:1085-95

21 Johannson KA, Vittinghoff $\mathrm{E}$, Lee $\mathrm{K}$, et al. Acute exacerbation of idiopathic pulmonary fibrosis associated with air pollution exposure. Eur Respir J 2014;43:1124-31.

22 Delfino RJ, Wu J, Tjoa T, et al. Asthma morbidity and ambient air pollution: effect modification by residential traffic-related air pollution. Epidemiology 2014;25:48-57.

23 Desquilbet L, Meyer L. [Time-dependent covariates in the Cox proportional hazards model. Theory and practice]. Rev Epidemiol Sante Publique 2005;53:51-68.

24 Ito K, Thurston GD, Silverman RA. Characterization of PM2.5, gaseous pollutants, and meteorological interactions in the context of time-series health effects models. J Expo Sci Environ Epidemiol 2007;17 Suppl 2(Suppl 2):S45-S60.

25 Johannson KA, Balmes JR, Collard HR. Air pollution exposure: a novel environmental risk factor for interstitial lung disease? Chest 2015;147:1161-7.

26 Europe, W. H. O. R. O. for \& Organization, W. H. Air Quality Guidelines: Global Update 2005 : Particulate Matter, Ozone, Nitrogen Dioxide, and Sulfur Dioxide. World Health Organization, 2006. 
27 Grahame TJ, Schlesinger RB. Oxidative stress-induced telomeric erosion as a mechanism underlying airborne particulate matter-related cardiovascular disease. Part Fibre Toxicol 2012;9:21.

28 Pope CA, Burnett RT, Thun MJ, et al. Lung cancer, cardiopulmonary mortality, and long-term exposure to fine particulate air pollution. JAMA 2002;287:1132-41.

29 Pope CA, Thun MJ, Namboodiri MM, et al. Particulate air pollution as a predictor of mortality in a prospective study of U.S. adults. Am J Respir Crit Care Med 1995; 151:669-74.

30 Alexis NE, Lay JC, Hazucha M, et al. Low-level ozone exposure induces airways inflammation and modifies cell surface phenotypes in healthy humans. Inhal Toxicol 2010;22:593-600.

31 Song $H$, Tan W, Zhang X. Ozone induces inflammation in bronchial epithelial cells. J Asthma 2011;48:79-83.
32 Meng YY, Rull RP, Wilhelm M, et al. Outdoor air pollution and uncontrolled asthma in the San Joaquin Valley, California. J Epidemiol Community Health 2010;64:142-7.

33 Collard HR, Ryerson CJ, Corte TJ, et al. Acute exacerbation of idiopathic pulmonary fibrosis. An International Working Group Report. Am J Respir Crit Care Med 2016;194:265-75.

34 Andersen ZJ, Bønnelykke K, Hvidberg M, et al. Long-term exposure to air pollution and asthma hospitalisations in older adults: a cohort study. Thorax 2012;67:6-11.

35 Peacock JL, Anderson HR, Bremner SA, et al. Outdoor air pollution and respiratory health in patients with COPD. Thorax 2011;66:591-6.

36 Hubbard R, Lewis S, Richards K, et al. Does ambient air pollution exposure modify longitudinal disease outcomes in a cohort of patients with idiopathic pulmonary fi brosis? Am J Respir Crit Care Med 2011;185:A5433. 